FACTA UNIVERSITATIS

Series: Physical Education and Sport Vol. 15, Nº 3, 2017, pp. 467 - 480

https://doi.org/10.22190/FUPES1703467C

Research article

\title{
FORCE-VELOCITY RELATIONSHIP OF LEG EXTENSORS OBTAINED FROM THREE DIFFERENT TYPES OF LOAD
}

\author{
UDC 796.012.1:531.5
}

\section{Marko Ćosić, Saša Đurić, Milena Živković, Aleksandar Nedeljković}

Faculty of Sport and Physical Education, University of Belgrade, Belgrade, Serbia

\begin{abstract}
The first aim of this study was to evaluate the shape of force-velocity $(F-V)$ relationships in case of gravitational $(W)$, inertial (I) and combined $(W+I)$ type of load assessed from squat jump (SJ) performed on a modified Smith machine. The second aim was to determine whether there were differences between the same parameters (maximal force, $F_{0}$; maximal velocity, $V_{0}$; maximal power, $P_{0}$ ) obtained from linear $F$-V relationship among three different loads. The third aim was to evaluate the concurrent validity of the parameters $F_{0}$ obtained from different types of load in SJ, with maximum isometric force in squat $\left(F_{i s o}\right)$, as well as one repetition maximum in squat (1RM). Fifteen male participants were tested in SJ with three different types of load, squat for obtaining 1RM and isometric squat for obtaining the $F_{i s o}$. The observed $F-V$ relationships were exceptionally strong and approximately linear (median $r \geq 0.98$ ) independently of used load. The differences between same parameters of different types of load were determined in parameters $F_{0}$ and $V_{0}$, while there were no differences between $P_{0}$. Regarding third aim, concurrent validity for $F_{0}$ showed to be moderate to high and significant in all 3 types of load $(r \geq 0.56)$, except between $F_{0}$ and $F_{\text {iso }}$ in $W$ type of load, where it was nonsignificant $(r \geq 0.47)$. The significance of the study reflects in better understanding of the mechanisms of the functioning of muscle system in case of different types of load. Future studies should investigate the impact of different types of load to kinetic and kinematic parameters in case of different motoric tasks and muscle groups.
\end{abstract}

Key words: Force-Velocity, Relationship, Inertia, Gravitation

\section{INTRODUCTION}

Sport, as well as other areas such as physical education, recreation, physical medicine and rehabilitation, sports and exercise medicine use motion and movement. The quality of performing them is largely determined by muscle mechanical properties such as force $(\mathrm{F})$,

Received November 16, 2017 / Accepted January 15, 2018

Corresponding author: Marko Ćosić

Faculty of Sport and Physical Education, University of Belgrade, Blagoja Parovića 156, 11000 Belgrade, Serbia Phone: +381(0)113531000•E-mail: profcosic@gmail.com 
velocity $(\mathrm{V})$ and power $(\mathrm{P})$. Although they are mutually dependent, the muscle mechanical properties mentioned are often evaluated isolated from each other. The example of this is testing of force, where standard tests most frequently provide information only on directly overcome external load (i.e. the result achieved when performing the test given). If we have in mind that muscle mechanical properties are affected by a greater number of factors, such as for example: muscle length, change in muscle length, speed of change and type of the muscle contraction (Kukolj, 2006), it is obvious that such tests reveal only a part of motor space. In support of that, there is also the fact that different muscle mechanical properties cannot be discerned when the single mechanical condition is applied within the testing procedure (Jarić, 2015). Therefore, in order to collect the information on different muscle mechanical properties, it is required to either increase the number of tests or increase the efficiency of testing. A greater number of tests leads to prolongation of the testing protocol and therefore, potentially, to the appearance of fatigue. As the solution to the problem occurred, we can offer the application of muscle force-velocity (F-V) relationship. Namely, only through the several load magnitudes of same motor task, we can calculate the parameters of maximum force $\left(\mathrm{F}_{0}\right)$, velocity $\left(\mathrm{V}_{0}\right)$ and power $\left(\mathrm{P}_{0}\right)$. Further, it is possible to evaluate the current level of abilities, optimize the training or evaluate the outcome of the conducted training programs (Đurić et al., 2016). Recent studies have shown that the F-V relationship obtained in multi-joint functional movements (walking, running, jumps, throwing, suppressions), is approximately linear, as well as it is a good indicator of the most significant muscle mechanical properties (Cuk et al., 2014; Dobrijević, Ilić, Đurić, \& Jarić, 2017; Driss \& Vandewalle, 2013; Samozino, Rejc, Di Prampero, Belli, \& Morin, 2012; Samozino, Rejc, di Prampero, Belli, \& Morin, 2014; Živković, Đurić, Čuk, Suzović, \& Jarić, 2017a), which speaks in favor of its practical application.

On the other hand, because of the entirely objective image of muscle mechanical properties, it is important to observe the nature of the type of load that is applied. Namely, in training and the competition itself, the athletes overcome certain external load which has two main components - gravitational and inertial - where their neglecting lessens the information power of the tests. Previous studies have examined the impact of the different types of loads to the effects of training (Anderson, Sforzo, \& Sigg, 2008; Galpin et al., 2015; Saeterbakken, Andersen, Kolnes, \& Fimland, 2014; Stevenson, Warpeha, Dietz, Giveans, \& Erdman, 2010; Wallace, Winchester, \& McGuigan, 2006). The findings of the studies mentioned have confirmed that application of different types of loads (usage of weights, rubber bands and their combination) lead to different effects of training. In support to this, there are also the results of the study which involved the impact of different types of loads on ballistic movements, where it was concluded that different load components differently affect the performances of the jumps, although the range of applied load magnitudes was relatively small (Leontijević et al., 2012). In addition, the studies of the impact of training with the application of negative and positive external load point out that training with a reduced gravitational load component enables greater progress in kinematic and kinetic parameters of the jump, as well as the training only with a negative load affected the specific changes in the mechanics of leg extensors, moving the parts of the F-V relationship (Marković, Vuk, \& Jarić, 2011). On the other hand, the studies that investigated the increase of inertial component of load to the vertical force of the ground reaction during walk and run, point out that its increase has a different impact on the parameters observed of the mentioned motor tasks (De Witt, Hagan, \& Cromwell, 2008). All of the above-mentioned points to the conclusion that the application of certain 
types of loads has a different impact to the muscle mechanical properties, and thus the necessity of respecting different components of loads is imposed.

Although the F-V relationship has become a new tendency in monitoring the muscle mechanical properties, we still need further studies in order to determine the reliability and validity of the mentioned method. Namely, only a few studies have studied the concurrent validity of the parameters of the linear F-V relationship. Concurrent validity of the parameter $\mathrm{F}_{0}$ in relation to directly measured muscle force, according to the results of some studies is moderate to high during activities such as cycling, jumping and bench press throwing (Čuk et al., 2014; Driss, Vandewalle, Chevalier, \& Monod, 2002; Srećković et al., 2015; Vandewalle, Peres, Heller, Panel, \& Monod, 1987), while according to other studies it is low in case of jumping (Rahmani, Viale, Dalleau, \& Lacour, 2001; Ravier, Grappe, \& Rouillon, 2004; Yamauchi \& Ishii, 2007). For that reason, concurrent validity of the parameter $\mathrm{F}_{0}$ is still a problem that must be investigated.

In accordance with the problems mentioned, the first aim of this study will be to evaluate the shape of the F-V relationship in case of gravitational (W), inertial (I) and combined $(\mathrm{W}+\mathrm{I})$ type of load assessed from the squat jump (SJ) performed on a modified Smith machine. Specifically, we will determine which optimal type of regression analysis describes the mentioned relations - linear or polynomial. The second aim of the study will be to execute the analysis and determine whether there are differences between the same parameters of the linear F-V relationship obtained in case of the mentioned types of loads. Then, it is required to analyze and compare the obtained parameters $\mathrm{F}_{0}$ in relation to standard procedures of the evaluation of muscle force. This will be done by an evaluation of concurrent validity of the parameters $F_{0}$ obtained from the F-V relationship in case of the $\mathrm{SJ}$, with one repetition maximum squat (1RM), as well as maximum isometric force in the squat $\left(\mathrm{F}_{\mathrm{iso}}\right)$, obtained on the dynamometer. This will be the third goal of the study. Potential findings of the study would contribute to the development of new methods for routine testing of $\mathrm{F}, \mathrm{V}$ and $\mathrm{P}$, and therefore better understanding of the functioning of the muscle system in case of different types of external load.

\section{Participants}

\section{METHODS}

In this study, 15 male participants (age $20.9 \pm 2.0$; body mass $82.5 \pm 5.9 \mathrm{~kg}$, body height $185.2 \pm 4.9 \mathrm{~cm}$, percent body fat $10.1 \pm 4.2 \%$, body mass index $24.0 \pm 1.6 \mathrm{~kg} / \mathrm{m}^{2}$ ), students of the Faculty of Sport and Physical Education, were recruited. Only those participants who had the experience with resistance training and who had $1 \mathrm{RM}$ from $130 \mathrm{~kg}$ to $150 \mathrm{~kg}(138.3 \pm 8.2$ $\mathrm{kg}$ ) were included. In addition, in order to establish significant differences at the alpha level of 0.05 and power 0.80 , at least 3 to 9 participants were required (Cohen, 1988). Therefore, of the greater number of potential candidates (40 interviewed), 15 who have met all the criteria mentioned were recruited. During the experiment, the participants were not active in any sports activities, but they were physically active through their standard academic curriculum which included activities in the range of at least 6 classes per week. Participants did not have injuries of the locomotor apparatus, no chronic diseases or heart problems. They were familiar with the possible risks and advantages of partaking in experiment. They signed a consent for taking part in the experiment, which was in accordance with Helsinki Declaration and it was approved by the Ethical Commission of the Faculty of Sport and Physical Education of the University in Belgrade. 


\section{Experimental Design and Protocol}

All the tests of this study were conducted on a modified Smith machine (see Fig. 1). Testing protocol consisted of the assessment of $F_{\text {iso }}$ and $1 \mathrm{RM}$, as well as SJ with 3 different types of load - W, I and W+I. The testing protocol consisted of 5 sessions among which there was at least 3 days of rest. The first testing session included anthropometric measurements, as well as familiarization of SJ with 3 different types of load and evaluation of $\mathrm{F}_{\text {iso. }}$. The participants' body mass and body height were assessed using the standard digital scale and anthropometer, respectively. The percentage of body fat was evaluated by a method of bioelectrical impedance. During the second session, there was familiarization of SJ performed with 3 different types of load, as well as assessment of 1RM. During the third, fourth and fifth session, the participants performed 2 attempts of SJ each with 7 different load magnitudes, all of that in case of 3 types of load. All sessions started with a standard warm up procedure -5 minutes of driving without load on a bicycle-ergometer, 8 minutes of mobilization exercises followed by specific warm up (see further text for details).

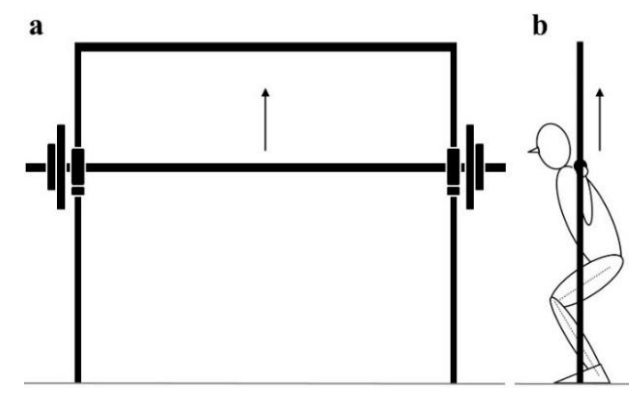

Fig. 1 Modified Smith machine and initial position for assessments of $F_{\text {iso }}$ and 1RM, as well as for SJ - from behind (a) and sideview (b).

\section{$F_{\text {iso }}$ and 1RM testing}

For the assessment of $\mathrm{F}_{\text {iso, }}$, the barbell was set so that the participant, holding it on his shoulders, achieved an angle of 90 degrees in his knees, where vertical projection of the barbell goes through the participant's thighs, lower legs and feet (see Fig. 1b). The feet were in the width of the shoulders and no arching of the back was allowed. The barbell was fixed and connected with dynamometer. For the assessment of $F_{\text {iso }}$, the participants performed 3 attempts each, pushing the fixed barbell for 4 seconds. The rest between 2 successive attempts was 3 minutes. The specific warm up contained 3 attempts of squats with progressively increased efforts of pushing the barbell.

For the assessment of 1RM, the initial position of the barbell was identical as for testing $\mathrm{F}_{\text {iso }}$ (see Fig. 1b). Each participant performed with the greatest possible load no more than 3 trials of squats, until he was unable to reach the full extension in the knees. Previously the greatest overcome load was taken as 1RM. Specific warm up implied 2 × 6 repetitions with $40 \%$ to $60 \%$ from the assumed $1 \mathrm{RM}$ based on the previously estimated $\mathrm{F}_{\text {iso. }}$. 


\section{SJ testing with 3 different types of load}

For the assessment of SJ with 3 different types of load, the initial position of the barbell was identical as for testing $F_{\text {iso }}$ (see Fig. 1b). The supporters, on a Smith machine, enabled the initial position for performing the test and exclusively concentric contraction of the muscles during SJ. This also prevented the lowering of the barbell below the initial position after the performance of the SJ. The participants performed SJ with 7 different load magnitudes with only one type of load per session. During each session, the load magnitudes were randomized, as well as the type of load during different testing sessions. In total, each participant overcame all 3 different types of load, with all 7 load magnitudes, i.e. 42 SJ ( 3 types of load $x 7$ load magnitudes $x 2$ attempts). The mass of the barbell was $20 \mathrm{~kg}$ and it represented a minimum load, while for higher loads there were weights added or/and rubber bands. In case of all 3 types of loads, total load which each participant overcame was equivalent to the mass of weights of $20 \mathrm{~kg}, 30 \mathrm{~kg}, 40 \mathrm{~kg}, 50 \mathrm{~kg}$, $60 \mathrm{~kg}, 70 \mathrm{~kg}$ and $80 \mathrm{~kg}$. Having in mind relatively small differences between participants, it was approximately 14\%, 21\%, 28\%, 35\%, 43\%, 50\% and 57\% from an averaged 1RM with all the participants. Not only did such a procedure simplify the protocol but it, first of all, provided the prevention of potential mistakes in case of different loads. The rest between different load magnitudes was 4 minutes, while between two successive attempts on the same load magnitude was 1 minute. Specific warm up was implemented in relation to the type of load which was applied on the testing, consisted of $2 \times 2$ SJ with the load that corresponded to a mass of $40 \mathrm{~kg}$.

\section{The testing device}

For the simulation of $\mathrm{W}$ and I, a standard Smith machine was modified with the additional construction which consisted of the frame, low friction and low inertia plastic wheels and rubber bands that were connected with ropes (see Fig. 2and 3).

Six parallel (3 on each side of the barbell), $14 \mathrm{~m}$ long rubber bands, were on one end attached to the barbell (free, moving end). Rubber bands (with ropes) were placed over the wheels system ( 7 or 6 depending on the type of load) and on their other end, over the rope, they were fixed by the brakes on the construction of the Smith machine. It is important to mention that in case of stretching rubber bands, their relative length was the only thing that changed and not their real length. This was enabled precisely by using non-stretchable ropes that were tied on the ends of rubber bands (see Fig. 3).

The change of the stretching magnitude of rubber bands and therefore the pulley force they make was performed by tightening the rope that entered the brake. Thus, the ropes were shortened in case of tightening rubber bands, rather than rubber bands themselves. The length of rubber bands was set to provide appropriate pulling force for each 2 successive attempts on the same load magnitude (previously, a probe of the dynamometer was used for calibration and to determine the extent of the pulling force in case of each stretching magnitude). The rubber bands' elasticity coefficient was $7,0 \mathrm{~N} / \mathrm{m}$, so each stretched rubber band in case of maximum length of $28 \mathrm{~m}$ applied a pulling force of $98 \mathrm{~N}$, i.e. load that corresponded to a mass of $10 \mathrm{~kg}$. Maximally stretched rubber bands mimicked the force which corresponded to the weights whose mass was $60 \mathrm{~kg}$. In case of the evaluation of W, the rubber bands pulled the barbell downward, while in case of evaluation I, the rubber bands pulled the barbell upward. The barbell displacement, i.e. change in the rubber bands 
length during SJ (while the legs of participants are in contact with the ground) was about 0.6 $\mathrm{m}$, i.e. less than $3 \%$ of their total length. In this way, during the SJ, the pulling force was relatively constant. It is important to mention that the weight of rubber bands was negligible.
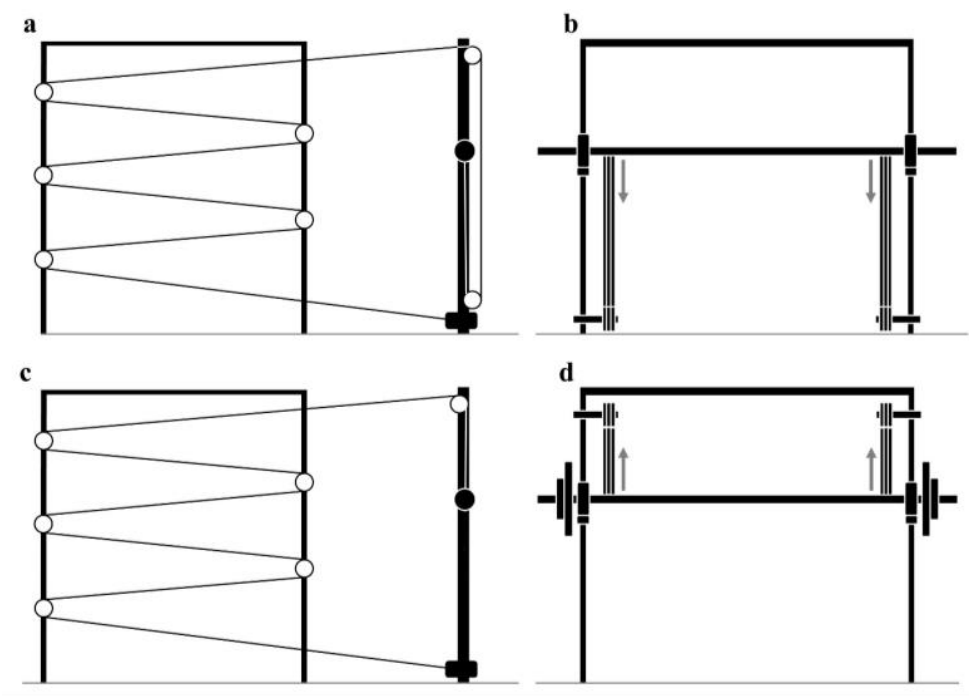

Fig. 2 Smith machine with additional construction with 7 or 6 wheels and rubber bands that were stretched to the maximal length, for assessment gravitational (a, sideview; b, from behind) or inertial type of load (c, sideview; d, from behind).

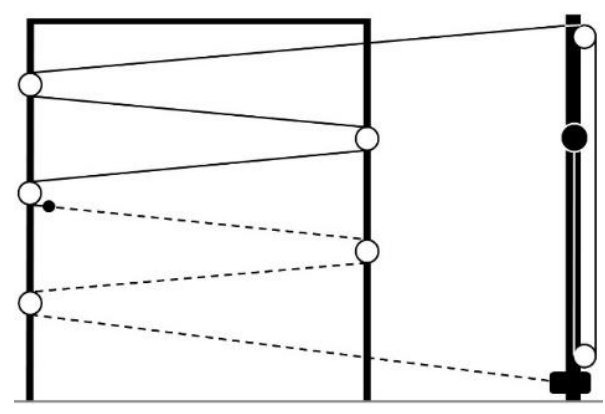

Fig. 3 The additional construction for assessment gravitational type of load with ropes (dashed line) and non-stretched rubber bands (solid line).

Three types of load were obtained with the barbell by adding the weight plates or/and rubber bands. For assessment of W, rubber bands pulling the barbell downward provided nearly constant force and therefore mimicked an increase in weight (see Fig. 2a and 2b). For assessment of I, on the barbell added weight plates were compensated by the rubber bands pulling upward (see Fig. 2c and 2d). It is important to mention that weight (mass $\mathrm{x}$ gravitation) of weight plates was compensated by the force by which the rubber bands pulled the barbell upward. Therefore, the total force mimicked an addition of solely inertia. For assessment of W+I, added weight plates to the barbell increased both the weight and inertia (see Fig. 1a). 


\section{Processing and analysis of data}

Vertical displacement of the barbell was recorded by using infrared cameras for $3 D$ kinematic analysis (Qualisys AB, Gothenburg, Sweden), with the frequency sampled at a rate of $240 \mathrm{~Hz}$. Movements velocity signals were processed by using Butterworth's low-pass filter of the second order of $10 \mathrm{~Hz}$ (Cronin, McNair, \& Marshall, 2000). Specially designed LabVIEW software was used to determine $\mathrm{F}$ and $\mathrm{V}$ variables from SJ. V and acceleration of the barbell were calculated as the first, i.e. second derivative of the movement, while $\mathrm{F}$ was calculated as the total sum of weight ( $\mathrm{m} \mathrm{x} \mathrm{g}$; mass multiplied by gravity acceleration) and inertia ( $\mathrm{m} \mathrm{x} \mathrm{a}$; mass multiplied by acceleration) of the total mass overcome (Đurić et al., 2016; Srećković et al., 2015; Živković et al., 2017a; Živković, Đurić, Čuk, Suzović, \& Jarić, 2017b). In case of assessment of W+Itotal force was represented by the sum of weight and inertia of the whole system, i.e. both the barbell and weights added, as well as the segments of the body which were moved along with the barbell. Those were the arms, head, trunk and upper legs (entire body except the feet and lower legs), i.e. total mass included $88 \%$ of the total mass of participants' bodies (calculated according to Dempster's model), as well as the mass of barbell and weights added. When we assessment $\mathrm{W}$, total force was represented by the sum of pulling force of rubber bands, and weight and inertia of the barbell and segments of the body that moved along with the barbell. Regarding I, total force was represented by the sum of weight and inertia of the barbell with weights and segments of the body that moved along with the barbell, reduced by the pulling force of rubber bands equivalent to the weight of the added weight plates. It is important to emphasize that external load of SJ included the mass of the barbell and mass of participants' body segments. Namely, it was inevitable that all 3 types of loads have both the W and I component due to the impossibility of neglecting mass of body segments that moved along with the barbell and the barbell itself which represented referent load (RL). Practically, different types of load were added to the body segments and RL, and that inevitably resulted in an increase in both $\mathrm{W}$ and I. Furthermore, $\mathrm{F}$ and $\mathrm{V}$ were calculated as average values during concentric phase of movement - from the time the barbell started moving until acceleration of the barbell dropped to $-9.81 \mathrm{~m} / \mathrm{s}^{2}$ (Cronin, Mcnair, \& Marshall, 2003; Đurić et al., 2016; Srećković et al., 2015).

\section{Statistical analysis}

In order to determine the normality of distribution of the dependent variables, we applied the Kolmogorov-Smirnov test, by which normal distribution of data was confirmed. In order to examine linearity of the F-V relationship in case of the 3 types of load, the linear regression analysis was applied. For the confirmation of linearity, polynomial regression analysis of the second order was implemented and the mentioned regression's confidence intervals were determined $(95 \% \mathrm{CI})$. Descriptive statistics were applied on the parameters of the linear F-V relationship as means and standard deviations. In order to determine the differences between the same parameters of the linear F-V relationship obtained in case of the 3 types of load, analysis of variance (ANOVA) was done. Determining concurrent validity of the parameter $\mathrm{F}_{0}$ in relation to directly measured force, was confirmed by the application of Pearson's correlation analysis. 


\section{RESULTS}

Figure 4. shows linear and polynomial F-V relationships assessed in SJ on Smith machine with 3 different types of load. In all 3 types of load we obtained approximately linear relation (median $r \geq 0.98$ ). Namely, medians of correlation coefficients obtained from linear regression in all 3 types of load enter the range of confidence intervals obtained from polynomial regression. We can observe that the obtained slope of regression line, which represents the relation of $\mathrm{F}$ and $\mathrm{V}$, depends on the type of the load applied. By observing the polynomial regressions, we can see that the shape of the regressions mentioned in case of $\mathrm{W}$ type of load is convex, while in case of $\mathrm{I}$ and $\mathrm{W}+\mathrm{I}$ type it is concave.
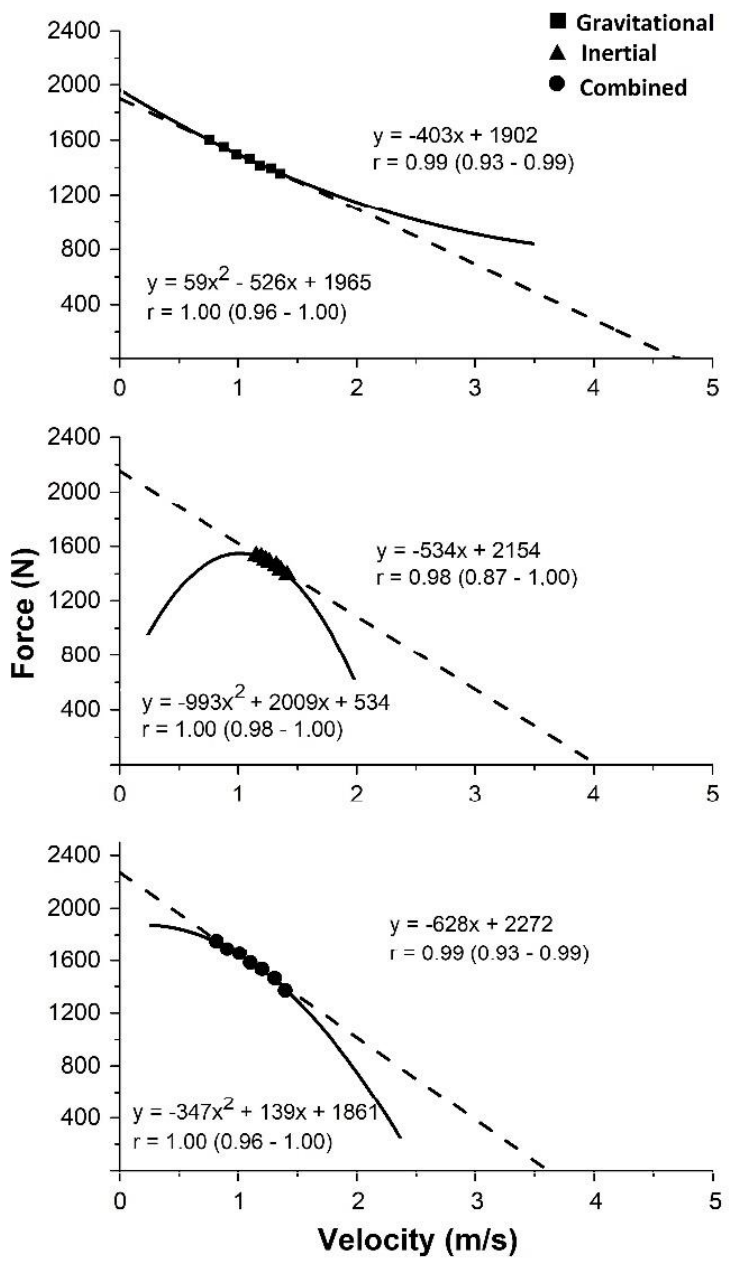

Fig. 4 Linear and polynomial F-V relationships of SJ on Smith machine in case of the three types of load averaged across the participants. The Figure shows regression forms, as well as median correlation coefficients with corresponding confidence intervals (CI 95\%). 
Table 1 Descriptive statistics of F-V relationship parameters.

\begin{tabular}{lccccc}
\hline Types of load & $\mathrm{F}_{0}$ & $\mathrm{~V}_{0}$ & $\mathrm{P}_{0}$ & $\mathrm{r}$ & $\mathrm{a}$ \\
\hline Gravitational & $1904 \pm 197$ & $4.9 \pm 1.0$ & $2332 \pm 448$ & $0.97 \pm 0.02$ & $405 \pm 110$ \\
Inertional & $2169 \pm 445$ & $4.5 \pm 1.8$ & $2346 \pm 561$ & $0.92 \pm 0.05$ & $534 \pm 255$ \\
Combined & $2260 \pm 164$ & $3.8 \pm 0.7$ & $2120 \pm 378$ & $0.96 \pm 0.03$ & $619 \pm 117$ \\
\hline
\end{tabular}

$\mathrm{F}_{0}$, force intercept; $\mathrm{V}_{0}$, velocity intercept, $\mathrm{P}_{0}$, maximum power; $r$, individual correlation coefficient from linear regression; a, slope of the regression line. Data are presented as mean and standard deviation.

In Table 1, there are descriptive statistics of the parameters obtained from the linear F$\mathrm{V}$ relationship. The highest value of $\mathrm{F}_{0}$ is obtained in case of $\mathrm{W}+\mathrm{I}$ type of load, while the highest $\mathrm{V}_{0}$ was calculated in $\mathrm{W}$ type of load. The lowest slope of F-V relationship was assessed in $\mathrm{W}$, while the highest was assessed in $\mathrm{W}+\mathrm{I}$ type of load.
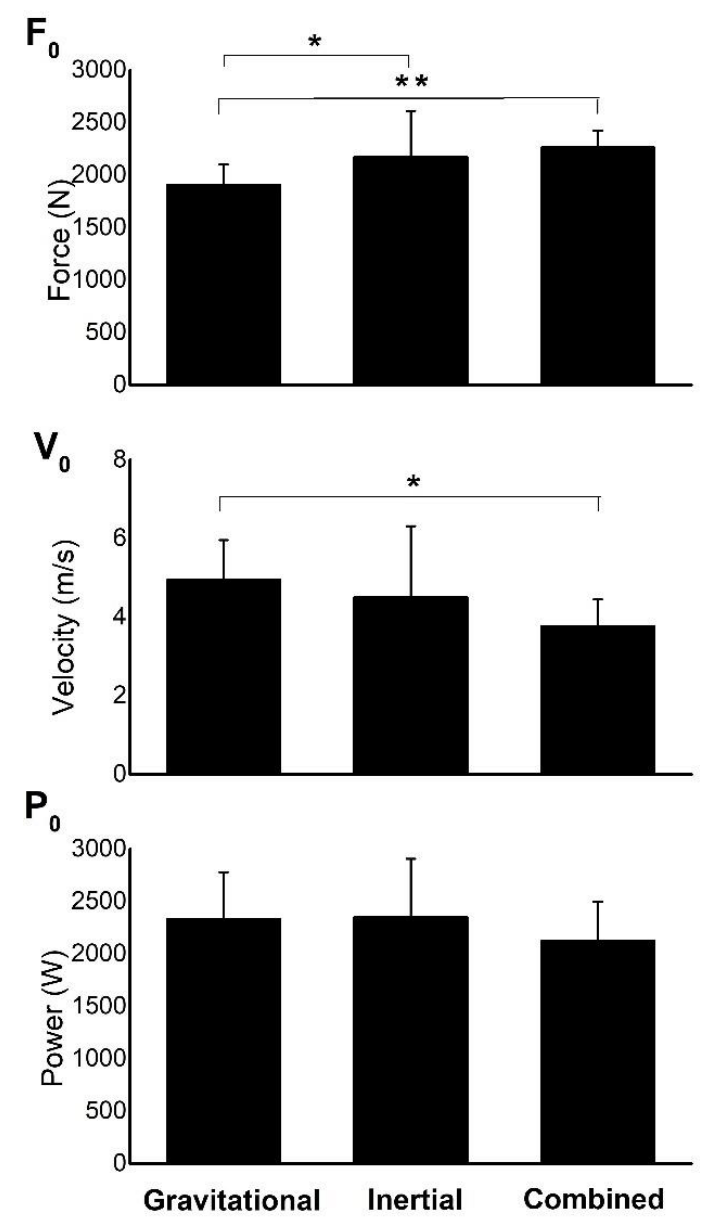

Fig. 5 The differences between the same parameters of the linear regression in a variety of types of load. ** $\mathrm{p}<0,01 ; * \mathrm{p}<0,05$. 
Figure 5. illustrates the differences between the same parameters $\left(\mathrm{F}_{0}, \mathrm{~V}_{0}\right.$ and $\left.\mathrm{P}_{0}\right)$ of linear regression in case of different types of loads in SJ. We can observe that there are differences determined in case of the parameters $\mathrm{F}_{0}$ and $\mathrm{V}_{0}$, while in case of parameter $\mathrm{P}_{0}$ there were no differences between different types of loads. Significant differences in case of $F_{0}$ were obtained between $\mathrm{W}+\mathrm{I}$ and $\mathrm{W}$, as well as $\mathrm{I}$ and $\mathrm{W}$ type of load. While in the case of $\mathrm{V}_{0}$, there was a significant difference observed only between $\mathrm{W}$ and $\mathrm{W}+\mathrm{I}$ type of load.

Table 2 Correlation of parameters of a linear regression and the directly measured variables of the maximum force

\begin{tabular}{llllll}
\hline Variables & $\mathrm{F}_{\text {iso }}$ & $1 \mathrm{RM}$ & $\mathrm{F}_{0 \_} \mathrm{W}$ & $\mathrm{F}_{0 \_} \mathrm{I}$ & $\mathrm{F}_{0 \_} \mathrm{W}+\mathrm{I}$ \\
\hline $\mathrm{F}_{\text {iso }}$ & 1 & & & & \\
$1 \mathrm{RM}$ & $0.79 * *$ & 1 & & & \\
$\mathrm{~F}_{0 \_} \mathrm{W}$ & 0.47 & $0.56 *$ & 1 & & \\
$\mathrm{~F}_{0 \_} \mathrm{I}$ & $0.63 *$ & $0.73 * *$ & 0.46 & 1 & \\
$\mathrm{~F}_{0 \_} \mathrm{W}+\mathrm{I}$ & $0.84 * *$ & $0.92 * *$ & $0.71 * *$ & $0.74 * *$ & 1 \\
\hline
\end{tabular}

$\mathrm{F}_{\text {iso, }}$, directly measured isometric force; $1 \mathrm{RM}$, directly measured one repetition maximum;

$\mathrm{F}_{0} \mathrm{~W}$, force intercept parameter in gravitational type of load; $\mathrm{F}_{0 \_} \mathrm{I}$, force intercept parameter in inertial type of load; $\mathrm{F}_{0} \mathrm{~W}+\mathrm{I}$, force intercept parameter in combined type of load.

Table 2. shows the correlations between the parameters of linear regressions in case of different types of load and directly measured variables of maximum force. As we can see from Table 2, the obtained correlation coefficients are moderate to high $(0,46 \leq \mathrm{r} \leq 0,92)$. Parameter of the maximum force obtained in W+I type of load highly and significantly correlated to the parameters obtained in W and I type of load, while they are mutually moderately correlated. As for the concurrent validity, a moderate to high and significant correlation between all the parameters $F_{0}$ and directly measured force $\left(F_{\text {iso }}\right.$ and 1RM) was also obtained, except between the parameter obtained in $\mathrm{W}$ type of load and $\mathrm{F}_{\text {iso }}$, where it was non-significant.

\section{DISCUSSION}

Within the present study, F-V relationships are evaluated in case of the 3 different types of load in SJ on Smith machine. According to the first aim, it was determined that the obtained F-V relationships in case of all types of load are approximately linear. In accordance with the second aim, it was shown that there are differences between the same parameters of the linear F-V relationship in case of different types of load. In accordance with the third aim, it was pointed to a high concurrent validity of the parameter $F_{0}$ in comparison to directly measured force in case of all 3 types of load.

Previous studies have shown that the F-V relationship in case of different multi-joint movements is approximately linear (Čuk et al., 2014; Dobrijević et al., 2017; Driss \& Vandewalle, 2013; Samozino, Rejc, Di Prampero, Belli, \& Morin, 2012; Samozino et al., 2014; Živković et al., 2017a). In addition, more and more studies that deal with these issues suggest that linear F-V relationship can be used in routine tests for the evaluation of muscle mechanical properties (Čuk et al., 2014; Jarić, 2015; Živković et al., 2017b). However, although it is shown that different types of load have a different effect on 
kinetic and kinematic parameters of movement, in previous studies their impact is mainly neglected. The results of this study have shown that by the application of $\mathrm{W}, \mathrm{I}$ and $\mathrm{W}+\mathrm{I}$ type of load in SJ we obtain approximately linear F-V relationship $(r \geq 0.98)$. Linearity is determined by the application of a polynomial regression model as well. As it was expected, the polynomial model has shown higher values of correlation coefficient; however, medians of correlation coefficient of the linear model were in the range of the polynomial model (see Fig. 4). Thus, we determine that the application of the linear model of F-V relationship is equally valid as the polynomial model. We must also keep in mind the fact that linear model is simpler for the usage and interpretation of the results, and accordingly the application of this model in case of different types of loads is desirable.

The obtained slopes of the linear F-V relationships are different in the aspect of the applied type of load (see Fig. 4). The slope of the regression line represents the relation of parameters of force and velocity, which points that the same parameters obtained from linear relationship are different in relation to the applied type of load. The obtained results of this study point out that $\mathrm{F}_{0}$ was the highest in case of $\mathrm{W}+\mathrm{I}$ and the lowest in case of $\mathrm{W}$ type of load. Such results can be explained by the fact that everyday human activity (walking, running, jumping) is affected by both components and thus the muscles on the legs are adapted and they are the most efficient in case of $\mathrm{W}+\mathrm{I}$ type of load. As for the parameter $\mathrm{V}_{0}$, the results have shown the highest value in case of $\mathrm{W}$ and the lowest in case of $\mathrm{W}+\mathrm{I}$ type of load. The results obtained can be explained by the lack of time for the muscles of the legs to develop maximum velocity in case of $\mathrm{W}+\mathrm{I}$ and I type of loads. Namely, in case of W type of load, muscles can develop maximum velocity of contraction at once because the component I of load is present only due to the mass of the body segments which are accelerated in case of the jump. However, in case of W+I and I type of load, there is also an additional inertia due to the mass of weights that are accelerated, in addition to the body segments mentioned. The fact that $\mathrm{V}_{0}$ was the least in $\mathrm{W}+\mathrm{I}$ type of load where both components are present (W and I), speaks in favor of the explanation suggested. Although the values of the parameters $\mathrm{F}_{0}$ and $\mathrm{V}_{0}$ were different, their product, parameter $\mathrm{P}_{0}$ was not significantly different in relation to the applied type of load.

In previous studies, concurrent validity of the parameter $\mathrm{F}_{0}$, was examined only in W+I type of load (Čuk et al., 2014; Driss et al., 2002; Srećković et al., 2015; Vandewalle et al., 1987). The results of this study have shown that concurrent validity of the parameter $F_{0}$ was moderate to high and significant in all 3 types of load, except between $F_{0}$ and $F_{\text {iso }}$ in $W$ type of load, where it was non-significant (see Table 2). This points out that parameter $\mathrm{F}_{0}$ has a real physiological meaning, i.e. that it can really describe the capacities of muscles to develop maximum force. The highest coefficients of correlations are obtained in case of parameter $F_{0}$ in relation to $F_{\text {iso }}(r=0,84)$ and $1 R M(r=0,92)$ in $\mathrm{W}+\mathrm{I}$ type of load. The results obtained also confirm that the $\mathrm{W}+\mathrm{I}$ type of load is the most present in case of everyday human activities. 


\section{CONCLUSION}

Based on the obtained results, we can conclude that the F-V relationship in SJ is approximately linear, independently from the applied type of load. The same parameters obtained from the linear F-V relationship are different in relation to the type of load. In addition, we obtained a high concurrent validity of the parameter $\mathrm{F}_{0}$. Such findings are in accordance with previous studies and they suggest that linear model can be applied in routine testing for the evaluation of muscle mechanical properties, independently from the applied type of load. However, the differences obtained between the same parameters in case of different types of load, as well as values of concurrent validity speak in favor of the fact that for the evaluation of muscle mechanical properties of the legs it is best to use combined type of load. The significance of the study reflects in better understanding of the mechanisms of the functioning of muscle system in case of different types of load. Future studies should investigate the impact of different types of load to kinetic and kinematic parameters in case of different motor tasks and muscle groups.

Acknowledgement: The study was supported by a grant from the Serbian Research Council (\#175037).

\section{REFERENCES}

Anderson, C. E., Sforzo, G. A., \& Sigg, J. A. (2008). The effects of combining elastic and free weight resistance on strength and power in athletes. The Journal of Strength \& Conditioning Research, 22(2), 567-574.

Cohen, J. (1988). Statistical power analysis for the behavioral sciences (2nd ed.). Hillsdale: Lawrence Erlbaum Associates.

Cronin, J. B., McNair, P. J., \& Marshall, R. N. (2000). The role of maximal strength and load on initial power production. Medicine and Science in Sports and Exercise, 32(10), 1763-1769.

Cronin, J. B., Mcnair, P. J., \& Marshall, R. N. (2003). Force-velocity analysis of strength-training techniques and load: implications for training strategy and research. The Journal of Strength \& Conditioning Research, 17(1), 148-155

Čuk, I., Marković, M., Nedeljković, A., Ugarković, D., Kukolj, M., \& Jarić, S. (2014). Force-velocity relationship of leg extensors obtained from loaded and unloaded vertical jumps. European Journal of Applied Physiology, 114(8), 1703-1714.

De Witt, J. K., Hagan, R. D., \& Cromwell, R. L. (2008). The effect of increasing inertia upon vertical ground reaction forces and temporal kinematics during locomotion. Journal of Experimental Biology, 211(7), 1087-1092.

Đurić, S., Čuk, I., Srećković, S., Mirkov, D., Nedeljković, A., \& Jarić, S. (2016). Selective effects of training against weight and inertia on muscle mechanical properties. International journal of Sports Physiology and Performance, 11(7), 927-932.

Dobrijević, S., Ilić, V., Đurić, S., \& Jarić, S. (2017). Force-velocity relationship of leg muscles assessed with motorized treadmill tests: Two-velocity method. Gait \& Posture, 56, 60-64.

Driss, T., \& Vandewalle, H. (2013). The measurement of maximal (anaerobic) power output on a cycle ergometer: a critical review. BioMed Research International, 2013, 1-40.

Driss, T., Vandewalle, H., Chevalier, J.-M. L., \& Monod, H. (2002). Force-velocity relationship on a cycle ergometer and knee-extensor strength indices. Canadian Journal of Applied Physiology, 27(3), 250-262.

Galpin, A. J., Malyszek, K. K., Davis, K. A., Record, S. M., Brown, L. E., Coburn, J. W., et al. (2015). Acute effects of elastic bands on kinetic characteristics during the deadlift at moderate and heavy loads. The Journal of Strength \& Conditioning Research, 29(12), 3271-3278.

Jarić, S. (2015). Force-velocity relationship of muscles performing multi-joint maximum performance tasks. International Journal of Sports Medicine, 36(09), 699-704. 
Kukolj, M. (2006). Antropomotorika (Anthropomotorics). Faculty of Sport and Physical Education, University of Belgrade. In Serbian

Leontijević, B., Pažin, N., Božić, P. R., Kukolj, M., Ugarković, D., \& Jarić, S. (2012). Effects of loading on maximum vertical jumps: Selective effects of weight and inertia. Journal of Electromyography and Kinesiology, 22(2), 286-293.

Marković, G., Vuk, S., \& Jarić, S. (2011). Effects of jump training with negative versus positive loading on jumping mechanics. International Journal of Sports Medicine, 32(5), 365-372.

Rahmani, A., Viale, F., Dalleau, G., \& Lacour, J.-R. (2001). Force/velocity and power/velocity relationships in squat exercise. European Journal of Applied Physiology, 84(3), 227-232.

Ravier, G., Grappe, F., \& Rouillon, J. (2004). Application of force-velocity cycle ergometer test and vertical jump tests in the functional assessment of karate competitor. Journal of Sports Medicine and Physical Fitness, 44(4), 349.

Saeterbakken, A. H., Andersen, V., Kolnes, M. K., \& Fimland, M. S. (2014). Effects of replacing free weights with elastic band resistance in squats on trunk muscle activation. The Journal of Strength \& Conditioning Research, 28(11), 3056-3062.

Samozino, P., Rejc, E., Di Prampero, P. E., Belli, A., \& Morin, J.B. (2012). Optimal Force-velocity profile in ballistic movements-altius. Medicine \& Science in Sports \& Exercise, 44(2), 313-322.

Samozino, P., Rejc, E., di Prampero, P.E., Belli, A., \& Morin, J.-B. (2014). Force-velocity properties' contribution to bilateral deficit during ballistic push-off. Medicine \& Science in Sports \& Exercise, 46(1), 107-114.

Srećković, S., Čuk, I., Đurić, S., Nedeljković, A., Mirkov, D., \& Jarić, S. (2015). Evaluation of force-velocity and power-velocity relationship of arm muscles. European journal of applied physiology, 115(8), 1779-1787.

Stevenson, M. W., Warpeha, J. M., Dietz, C. C., Giveans, R. M., \& Erdman, A. G. (2010). Acute effects of elastic bands during the free-weight barbell back squat exercise on velocity, power, and force production. The Journal of Strength \& Conditioning Research, 24(11), 2944-2954.

Vandewalle, H., Peres, G., Heller, J., Panel, J., \& Monod, H. (1987). Force-velocity relationship and maximal power on a cycle ergometer. European Journal of Applied Physiology and Occupational Physiology, 56(6), 650-656.

Wallace, B. J., Winchester, J. B., \& McGuigan, M. R. (2006). Effects of elastic bands on force and power characteristics during the back squat exercise. Journal of Strength and Conditioning Research, 20(2), 268.

Yamauchi, J., \& Ishii, N. (2007). Relations between force-velocity characteristics of the knee-hip extension movement and vertical jump performance. Journal of Strength and Conditioning Research, 21(3), 703.

Živković, M. Z., Đurić, S., Čuk, I., Suzović, D., \& Jarić, S. (2017a). Muscle force-velocity relationships observed in four different functional tests. Journal of Human Kinetics, 56(1), 39-49.

Živković, M. Z., Đurić, S., Čuk, I., Suzović, D., \& Jarić, S. (2017b). A simple method for assessment of muscle force, velocity, and power producing capacities from functional movement tasks. Journal of Sports Sciences, 35(13), 1287-1293.

\section{ODNOS SILA-BRZINA OPRUŽAČA NOGU DOBIJEN PRI TRI RAZLIČITE VRSTE OPTEREĆENJA}

Prvi cilj studije bio je da se ispita oblik relacije sila-brzina $(F-V)$ pri skoku iz polučučnja (SJ) na modifikovanoj Smit mašini, pri gravitacionoj (W), inercionoj (I) i kombinovanoj (W+I) vrsti opterećenja. Drugi cilj bio je da se utvrdi ima li razlika između istih parametara (maksimalna sila, $F_{0}$; maksimalna brzina, $V_{0}$; maksimalna snaga, $P_{0}$ ) dobijenih iz linearne $F-V$ relacije pri različitim vrstama opetrećenja. Treći cilj bio je da se ispita konkurentna validnost parametra $F_{0}$ dobijenog pri različitim vrstama opterećenja kod SJ, sa maksimalnom izometrijskom silom ( $\left.F_{\text {iso }}\right)$, kao i sa maksimalnim podignutim opterećenjem iz polučučnja (1RM). Petnaest muških ispitanika testirano je pri SJ sa tri različite vrste opterećenja, kao i pri polučučnju za dobijanje 1RM i polučučnju u

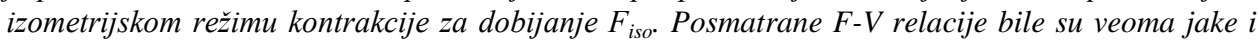
približno linearne (medijana $r \geq 0.98$ ), bez obzira na primenjeno opterećenje. Razlike između istih parametara dobijenih pri tri različite vrste opterećenja su ustanovljene za parametre $F_{0} i V_{0}$, dok $z a P_{0}$ razlike nisu uočene. Što se trećeg cilja tiče, konkurentna validnost za $F_{0}$ bila je umerena do 
visoka $i$ značajna pri sve tri vrste opterećenja $(r \geq 0.56)$, osim između $F_{0} i F_{\text {iso }}$ pri $W$ tipu opterećenja, gde ona nije značajna $(r \geq 0.47)$. Značaj ove studije ogleda se u boljem razumevanju mehanizama funkcionisanja mišića u slučaju primene različitih vrsta opterećenja. Buduća istraživanja trebalo bi da istraže uticaj različitih vrsta opterećenja na kinetičke i kinematičke parametre u slučaju različitih motoričkih zadataka i mišićnih grupa.

Ključne reči: sila-brzina, relacija, inercija, gravitacija 